\title{
Microstructural evolution of h-BN matrix composite ceramics with La-Al-Si-O glass phase during hot-pressed sintering
}

\author{
Baofu QIU ${ }^{a, b}$, Xiaoming DUAN ${ }^{a, b, c, *}$, Zhuo ZHANG ${ }^{a, b}$, Chen $\mathrm{ZHAO}^{a, b}$, Bo NIU ${ }^{a, b}$, \\ Peigang $\mathrm{HE}^{a, b, *}$, Delong $\mathrm{CAI}^{a, b}$, Lei $\mathrm{CHEN}^{a, b}$, Zhihua YANG ${ }^{a, b, c}$, \\ Yujin WANG ${ }^{a, b}$, Dechang JIA ${ }^{a, b, c, *}$, Yu ZHOU ${ }^{a, b}$ \\ ${ }^{a}$ Key Laboratory of Advanced Structural-Functional Integration Materials \& Green Manufacturing Technology, \\ Harbin Institute of Technology, Harbin 150001, China \\ ${ }^{b}$ Institute for Advanced Ceramics, School of Materials Science and Engineering, Harbin Institute of \\ Technology, Harbin 150001, China \\ ${ }^{c}$ State Key Laboratory of Advanced Welding and Joining, Harbin Institute of Technology, Harbin 150001, China
}

Received: September 7, 2020; Revised: December 5, 2020; Accepted: December 24, 2020

(C) The Author(s) 2020.

\begin{abstract}
BN} / \mathrm{La}-\mathrm{Al}-\mathrm{Si}-\mathrm{O}$ composite ceramics were fabricated by hot-pressed sintering using hexagonal boron nitride (h-BN), lanthanum oxide $\left(\mathrm{La}_{2} \mathrm{O}_{3}\right)$, aluminia $\left(\mathrm{Al}_{2} \mathrm{O}_{3}\right)$, and amorphous silica $\left(\mathrm{SiO}_{2}\right)$ as the raw materials. The effects of sintering temperature on microstructural evolution, bulk density, apparent porosity, and mechanical properties of the h-BN composite ceramics were investigated. The results indicated that $\mathrm{La}-\mathrm{Al}-\mathrm{Si}-\mathrm{O}$ liquid phase was formed during sintering process, which provided an environment for the growth of h-BN grains. With increasing sintering temperature, the cristobalite phase precipitation and h-BN grain growth occurred at the same time, which had a significant influence on the densification and mechanical properties of h-BN composite ceramics. The best mechanical properties of $\mathrm{BN} / \mathrm{La}-\mathrm{Al}-\mathrm{Si}-\mathrm{O}$ composite ceramics were obtained under the sintering temperature of $1700{ }^{\circ} \mathrm{C}$. The elastic modulus, flexural strength, and fracture toughness were $80.5 \mathrm{GPa}$, 266.4 $\mathrm{MPa}$, and $3.25 \mathrm{MPa} \cdot \mathrm{m}^{1 / 2}$, respectively.
\end{abstract}

Keywords: h-BN matrix composite ceramics; La-Al-Si-O glass phase; microstructural evolution; nanocrystalline precipitation; mechanical properties

\section{Introduction}

Hexagonal boron nitride (h-BN) and its matrix composite ceramics are typical structural-functional ceramics that

\footnotetext{
* Corresponding authors.

E-mail: X. Duan, dxmhit@126.com;

P. He, peiganghe@hit.edu.cn;

D. Jia, dcjia@hit.edu.cn
}

have been widely used in many fields, such as aerospace, machinery, metallurgy, energy, and electronics [1-7]. Compared with alumina, zirconia, silicon carbide, and silicon nitride ceramic, which have the high hardness and high strength, h-BN presents the relatively low hardness and good machinable properties because of its hexagonal layered crystal structure similar to that of graphite [8-11]. Furthermore, h-BN ceramics are difficult to sintering densification, so the low melting point sintering additives and/or second phase are usually 
added to improve the properties of h-BN composite ceramics [12-16].

Some researches have been investigated on the microstructural evolution during sintering and the properties of h-BN ceramics [17-21]. Zhang et al. [22] obtained h-BN powders composed of amorphous and nanocrystalline $\mathrm{BN}$ by ball milling, and then sintered them under different temperatures and pressures. Higher sintering pressure was more favorable to the preferred orientation growth of the in-plane direction of h-BN grains along the pressure direction, and higher sintering temperature promoted the mass transfer and grain growth. They referred that the structural fluctuation of amorphous $\mathrm{BN}$ resulted in the turbostratic boron nitride (t-BN) phase formation during the sintering process, and stacking faults usually existed in the as-grown h-BN grains [22].

For h-BN matrix composite ceramics, some research results have revealed the microstructure changing mechanisms [23-28]. Niu et al. [29] investigated the effects of raw h-BN particle size on the textured microstructures of magnesium aluminosilicate (BN-MAS) composite ceramics. With the increase of raw h-BN particle size, $\mathrm{h}-\mathrm{BN}$ grains tended to orientate with the direction perpendicular to the hot-pressing direction, and the densification effect of MAS phase on BN-MAS composite ceramics decreased with increasing raw h-BN particle size due to the uneven dispersion of MAS phase [26,29]. Cai et al. [30-32] researched the influence of sintering process on the BN-MAS composite ceramics. The sintering pressure had a great influence not only on the mechanical properties of composite ceramics, but also on the crystallization of MAS and structural order of h-BN. The nucleophilic attack of $\mathrm{N}$ on $\mathrm{M}$ $\left(\mathrm{M}=\mathrm{Mg}^{2+}, \mathrm{Al}^{3+}\right.$, and $\left.\mathrm{Si}^{4+}\right)$ and the electrophilic attack of $\mathrm{B}$ on $\mathrm{O}$ were the crucial factors on the formation of amorphous MAS phase. In addition, chemical bonding was formed between h-BN and MAS, and the matrix atoms diffused into the h-BN layers, leading to a strong bonding interface [30-32].

$\mathrm{La}-\mathrm{Al}-\mathrm{Si}-\mathrm{O}$ glass phase has been reported on promoting sintering densification and improving the room/elevated-temperature mechanical properties of h-BN matrix composite ceramics [33-37]. However, the microstructural evolution during sintering process and its effect on properties of these material systems have not been fully revealed yet, which also has important implications for guiding the composition design and process optimization of composite ceramics.
In this study, $\mathrm{BN} / \mathrm{La}-\mathrm{Al}-\mathrm{Si}-\mathrm{O}$ composite ceramics were sintered under different temperatures from 1500 to $1900{ }^{\circ} \mathrm{C}$. The phase composition, nanocrystalline precipitation, and grain growth were systematically investigated. The corresponding mechanical properties were tested to reveal the influence of microstructural evolution on the performance of composite ceramics.

\section{Experimental}

\section{1 Material fabrication}

Commercial powders of h-BN $(99.5 \%, 0.3 \mu \mathrm{m}$, Advanced Technology \& Materials Co., Ltd., China), hexagonal $\mathrm{La}_{2} \mathrm{O}_{3}(99.9 \%, 1.0 \mu \mathrm{m}$, Wuxi Meifang Industry Co., Ltd., China), rhombohedral $\mathrm{Al}_{2} \mathrm{O}_{3}(>98 \%, 1.5 \mu \mathrm{m}$, Showa Denko K.K., Yokohama, Japan), and amorphous $\mathrm{SiO}_{2}(99.9 \%, 3.5 \mu \mathrm{m}$, Lianyungang Guangyu Quartz Co., Ltd., China) were used as the raw materials. The volume ratio of h-BN: $\left(\mathrm{La}_{2} \mathrm{O}_{3}-\mathrm{Al}_{2} \mathrm{O}_{3}\right): \mathrm{SiO}_{2}$ was 70:10:20, and the mole ratio of $\mathrm{La}_{2} \mathrm{O}_{3}: \mathrm{Al}_{2} \mathrm{O}_{3}$ was $1: 2$.

The weighed powders were mixed with $\mathrm{Al}_{2} \mathrm{O}_{3}$ balls and ethanol medium for $12 \mathrm{~h}$. The obtained slurry was dried, and then passed through a 100-mesh sieve. The mixed powders were put into a graphite die and cold-compacted uniaxially under $5 \mathrm{MPa}$ pressure. The obtained green compacts were hot-press sintered at different temperatures for $1 \mathrm{~h}$ under $20 \mathrm{MPa}$ with $\mathrm{N}_{2}$ atmosphere to maintain the partial pressure of nitrogen and prevent $\mathrm{h}-\mathrm{BN}$ decomposition. The heating rate was $15{ }^{\circ} \mathrm{C} \cdot \mathrm{min}^{-1}$ and the samples cooled down to room temperature in the furnace spontaneously. According to the phase diagram of $\mathrm{La}-\mathrm{Al}-\mathrm{Si}-\mathrm{O}$ system, liquid phase can be formed at about $1700{ }^{\circ} \mathrm{C}$. Therefore, the sintering temperatures from 1500 to $1900{ }^{\circ} \mathrm{C}$ were chosen in this study.

\section{2 Material characterization}

Phase compositions were identified by X-ray diffractometer (XRD, D/max- $\gamma \mathrm{B} \mathrm{Cu} \mathrm{K} \alpha$, Rigaku Co., Japan) with a scanning speed of $4\left(^{\circ}\right) \cdot \mathrm{min}^{-1}$. The detailed microstructures were investigated by transmission electron microscope (TEM, Talos F200X, FEI Co., USA), and the concentration of elements was detected by scanning electron microscope (SEM) equipped with energy dispersive spectroscopy (EDS, EDAX Inc., Mahwah, NJ, USA) detector. The TEM samples were firstly cut into the small pieces with the thickness of 
about $0.2 \mathrm{~mm}$, and then polished to about $0.07 \mathrm{~mm}$ by 2000-mesh abrasive paper. Ar ion etching instrument was used to create thin regions to meet the requirement of TEM observation. The bulk densities and apparent porosities of samples were measured by Archimedes law referring to the China National Standard GB/T 25995-2010. The flexural strength was measured by three-point bending method using a universal testing machine (Instron-5569, USA), and Young's modulus was obtained through the stress-strain curve. The sample size was $3 \mathrm{~mm} \times 4 \mathrm{~mm} \times 36 \mathrm{~mm}$ with a span of $30 \mathrm{~mm}$ and the crosshead speed was $0.5 \mathrm{~mm} \cdot \mathrm{min}^{-1}$. The loading direction was perpendicular to the sintering pressure direction. Fracture toughness was measured using the single edge notched beam (SENB) method. The sample size was $2 \mathrm{~mm} \times 4 \mathrm{~mm} \times 20 \mathrm{~mm}$ with a notch of $2 \mathrm{~mm}$, and the crosshead speed was $0.05 \mathrm{~mm} \cdot \mathrm{min}^{-1}$. The fracture morphologies were observed using SEM (NanoLab 600i, FEI Co., USA).

\section{Results and discussion}

Figure 1(a) presents the XRD of $\mathrm{BN} / \mathrm{La}-\mathrm{Al}-\mathrm{Si}-\mathrm{O}$ composite ceramics sintered under different temperatures. There were only obvious diffraction peaks corresponding to h-BN phase (JCPCPDF 34-0421), whereas the diffraction peaks of $\mathrm{La}_{2} \mathrm{O}_{3}, \mathrm{Al}_{2} \mathrm{O}_{3}, \mathrm{SiO}_{2}$, and their possible reaction products were not found. Considering the total volume content of the adding $\mathrm{La}-\mathrm{Al}-\mathrm{Si}-\mathrm{O}$ was about $30 \%$, which had exceeded the minimum threshold of XRD detection. Thus, we inferred that the amorphous glass phase was formed during hot-pressed sintering process, which was difficult to be characterized by XRD.

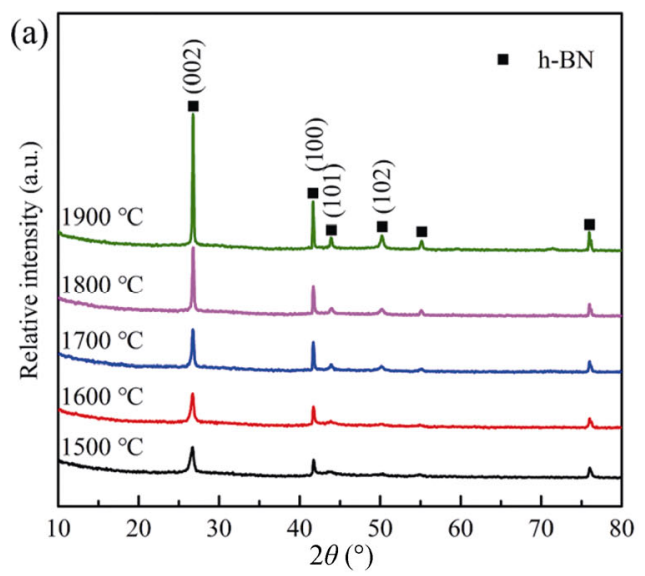

Comparing with the peaks of h-BN in different composite ceramics, with the increase of sintering temperature, the relative peak intensity of the corresponding (002) lattice plane increased gradually. Graphitizing index $(G I)$ is an indicator of crystallization degree of graphite and similar crystalline structure materials [38], and it is calculated by the following equation:

$$
G I=\frac{\operatorname{Area}(100)+\operatorname{Area}(101)}{\operatorname{Area}(102)}
$$

where $\operatorname{Area}(100)$, Area(101), and Area(102) denote the integral intensity intensities of the corresponding $(h k l)$ reflexes of h-BN. Theoretically, the $G I$ value of ideal h-BN crystal is about 1.6 , and a lower $G I$ value is corresponded to better crystallization of h-BN grains.

Figure 1(b) shows the calculated $G I$ values of h-BN grains in composite ceramics. With the increase of sintering temperature, $G I$ values showed a decreasing trend, which basically conformed to the change rule of exponential function. From 1500 to $1700{ }^{\circ} \mathrm{C}$, the GI value decreased rapidly from 13.7 to 3.4 ; and from 1700 to $1900{ }^{\circ} \mathrm{C}$, the $G I$ value decreased slowly from 3.4 to 2.4 . The sintering temperature had a significant influence on the crystallization growth of h-BN in composite ceramics. The higher sintering temperature was conducive to heat and mass transfer in liquid phase environment, and the better h-BN grains grow during hot-pressed sintering.

In Figs. 2(a)-2(c), TEM characterization was used to investigate the detail microstructures of $\mathrm{BN} / \mathrm{La}-\mathrm{Al}-\mathrm{Si}-\mathrm{O}$ composite ceramics hot-press sintered under 1500 , 1700 , and $1900{ }^{\circ} \mathrm{C}$, and the corresponding element distributions of $\mathrm{B}, \mathrm{N}, \mathrm{O}, \mathrm{Al}, \mathrm{Si}$, and $\mathrm{La}$ were shown in Fig. 2(d). The h-BN grains showed typical lamellar morphologies and were uniformly dispersed in all the

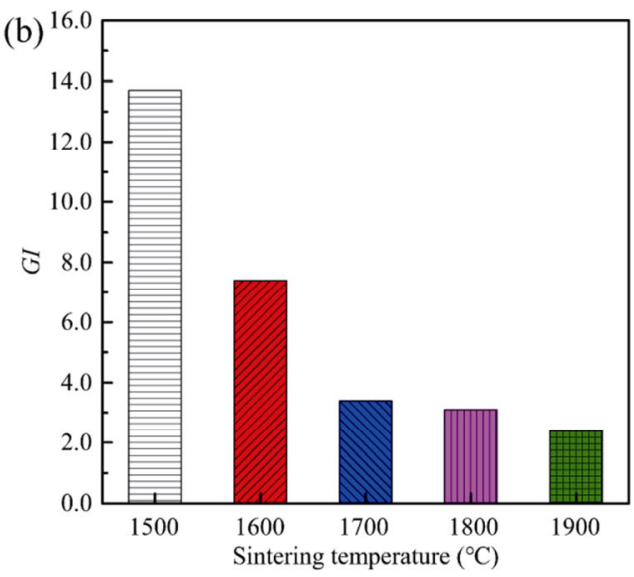

Fig. 1 (a) XRD patterns and (b) crystallization $G I$ of $\mathrm{BN} / \mathrm{La}-\mathrm{Al}-\mathrm{Si}-\mathrm{O}$ composite ceramics. 

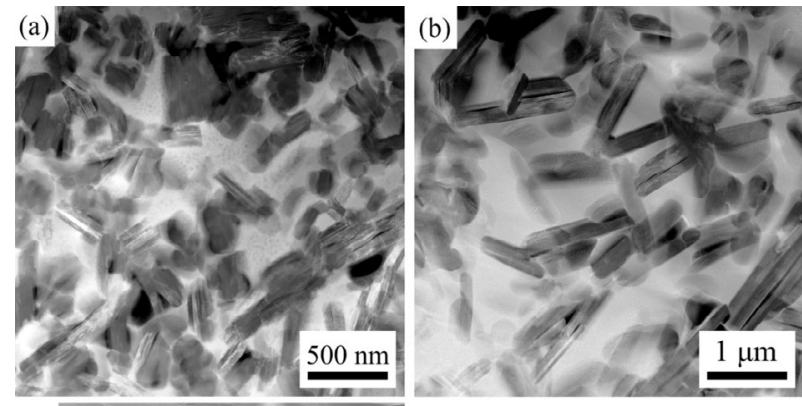

(c)

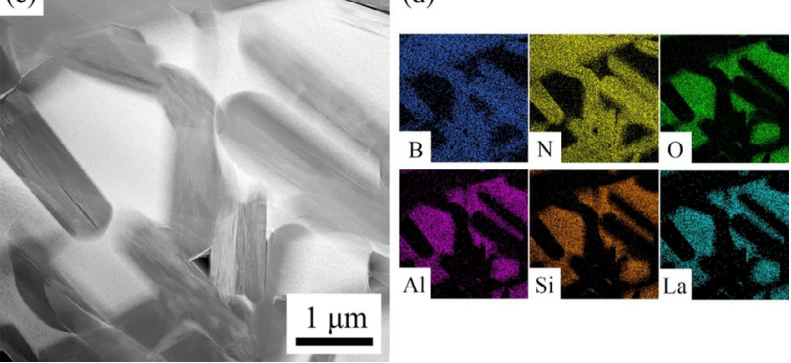

Fig. 2 Microstructures of $\mathrm{BN} / \mathrm{La}-\mathrm{Al}-\mathrm{Si}-\mathrm{O}$ composite ceramics sintered under different temperatures: (a) 1500, (b) 1700 , and (c) $1900{ }^{\circ} \mathrm{C}$; (d) $\mathrm{B}, \mathrm{N}, \mathrm{O}, \mathrm{Al}, \mathrm{Si}$, and $\mathrm{La}$ element distribution corresponding to the sample in (c) that sintered at $1900{ }^{\circ} \mathrm{C}$.

composite ceramics. $\mathrm{La}-\mathrm{Al}-\mathrm{Si}-\mathrm{O}$ glass phase filled in the space between h-BN grains and had a good combination with h-BN grains, and there were few obvious interfacial cracks. It could be obviously observed that the grain size of $\mathrm{h}-\mathrm{BN}$ became bigger with increasing sintering temperature, because the liquid phase had better heat and mass transfer effect at higher temperatures to promote the growth of h-BN grains.

Some pores were observed in the sample sintered at $1500{ }^{\circ} \mathrm{C}$. This was due to the relatively low fluidity of the liquid phase at this sintering temperature, which could not fully fill the gaps between the h-BN grains. However, in the sample sintered at $1900{ }^{\circ} \mathrm{C}$, a small number of pores were also found. This was because the grown h-BN grains overlapped each other to form closed pores, which could not be filled by liquid phase. By contrast, no obvious pores were found in the sample sintered at $1700{ }^{\circ} \mathrm{C}$, indicating this sintering temperature was favorable for obtaining composite ceramics with high relative densities.

Interface microstructures between $\mathrm{h}-\mathrm{BN}$ grains and $\mathrm{La}-\mathrm{Al}-\mathrm{Si}-\mathrm{O}$ phase of composite ceramics sintered under different temperatures are presented in Figs. 3(a)-3(c), and the corresponding elemental line scanning profiles from $\mathrm{h}-\mathrm{BN}$ zone to $\mathrm{La}-\mathrm{Al}-\mathrm{Si}-\mathrm{O}$ zone are shown in Figs. 3(d)-3(f). No defects such as crack could be observed at the phase boundary, indicating a good wettability between $\mathrm{La}-\mathrm{Al}-\mathrm{Si}-\mathrm{O}$ glass phase and $\mathrm{h}-\mathrm{BN}$ grains. The changes of elemental contents were continuous. $\mathrm{La}, \mathrm{Al}, \mathrm{Si}$, and $\mathrm{O}$ content of glass phase increased, whereas $\mathrm{B}$ and $\mathrm{N}$ content of h-BN phase decreased gradually along the arrow direction. When the sintering temperature increased from 1500 to $1900{ }^{\circ} \mathrm{C}$, the width of the measuring diffusion zone of three samples ( $\mathrm{h}-\mathrm{BN}$ grains and $\mathrm{La}-\mathrm{Al}-\mathrm{Si}-\mathrm{O}$ glass phase of composite ceramics sintered under 1500, 1700, and $1900{ }^{\circ} \mathrm{C}$ ) at the two phase interface increased from about 38 to more than $55 \mathrm{~nm}$, indicating higher sintering temperatures were more beneficial to the element diffusion in the phase interface region during hot-pressed sintering process. In Fig. 3(g), high-resolution transmission electron microscopy (HRTEM) results exhibited the detailed interface zone formed by atom diffusion between $\mathrm{La}-\mathrm{Al}-\mathrm{Si}-\mathrm{O}$ glass phase and the h-BN phase, which showed a gradual transition from order to disorder arrangement. On the whole, continuous, defect-free, and mutually diffusive grain boundary was beneficial to provide the good interface bonding and better performance of composite ceramics.

As shown in Figs. 4(a)-4(c), the precipitation nanocrystalline was also found in $\mathrm{La}-\mathrm{Al}-\mathrm{Si}-\mathrm{O}$ glass phase, and with the increase of sintering temperature, the size of these precipitated grains showed a gradual increasing trend. High sintering temperature was more likely to form precipitation phase with bigger size. Through selecting electron diffraction analysis in Fig. 4(d), the precipitated phase was identified as cristobalite, which meant the precipitated cristobalite phase and $\mathrm{La}-\mathrm{Al}-\mathrm{Si}-\mathrm{O}$ glass phase were coexisted in the composite ceramics. This phenomenon was also reported in the similar multiple oxide systems, such as $\mathrm{CaO}-\mathrm{Al}_{2} \mathrm{O}_{3}-\mathrm{SiO}_{2}$, $\mathrm{La}_{2} \mathrm{O}_{3}-\mathrm{Al}_{2} \mathrm{O}_{3}-\mathrm{SiO}_{2}$, and $\mathrm{Y}_{2} \mathrm{O}_{3}-\mathrm{Al}_{2} \mathrm{O}_{3}-\mathrm{SiO}_{2}$. Inhomogeneous nucleation in glass phase is the main reason for the formation of cristobalite nanocrystals $[39,40]$.

Figure 5 shows the bulk densities and apparent porosities of $\mathrm{BN} / \mathrm{La}-\mathrm{Al}-\mathrm{Si}-\mathrm{O}$ composite ceramics sintered under different temperatures. With the increase of sintering temperature, bulk density of h-BN composite ceramics first increased and then decreased, whereas apparent porosity exhibited the opposite tendency. The composite ceramic sintered at $1700{ }^{\circ} \mathrm{C}$ had the highest bulk density and the lowest apparent porosity. With the increase of sintering temperature, the liquid phase had better fluidity and wettability, and could well fill into the voids formed by the overlap of h-BN 

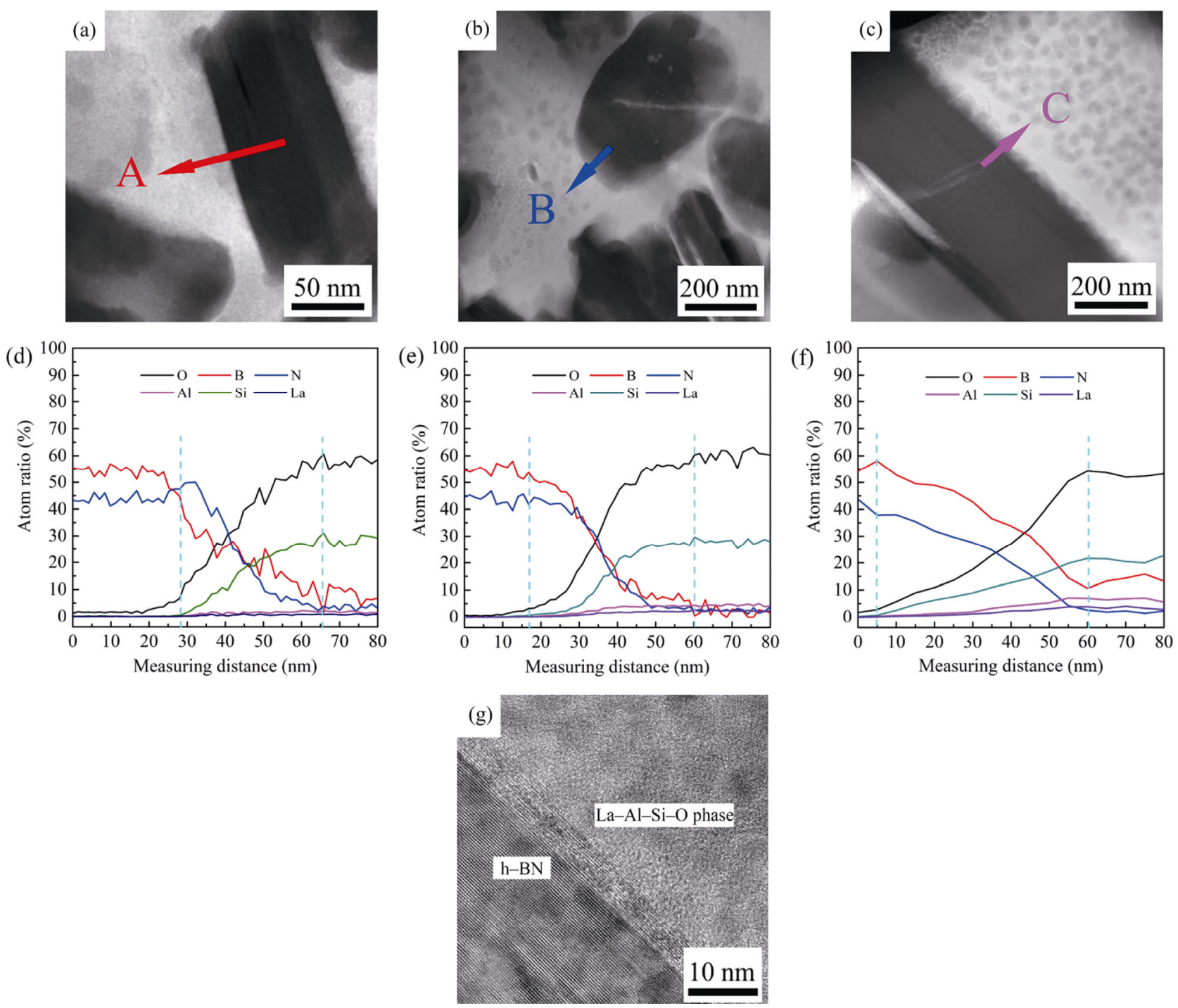

Fig. 3 Interface microstructures between $\mathrm{h}-\mathrm{BN}$ grains and $\mathrm{La}-\mathrm{Al}-\mathrm{Si}-\mathrm{O}$ glass phase of composite ceramics sintered under different temperatures: (a) 1500, (b) 1700, and (c) $1900{ }^{\circ} \mathrm{C}$; (d-f) elemental line scannings corresponding to lines $\mathrm{A}, \mathrm{B}$, and $\mathrm{C}$ in $(\mathrm{a}-\mathrm{c})$, respectively; $(\mathrm{g}) \mathrm{HRTEM}$ corresponding to the interface of $\mathrm{La}-\mathrm{Al}-\mathrm{Si}-\mathrm{O}$ phase and h-BN grain in (c).
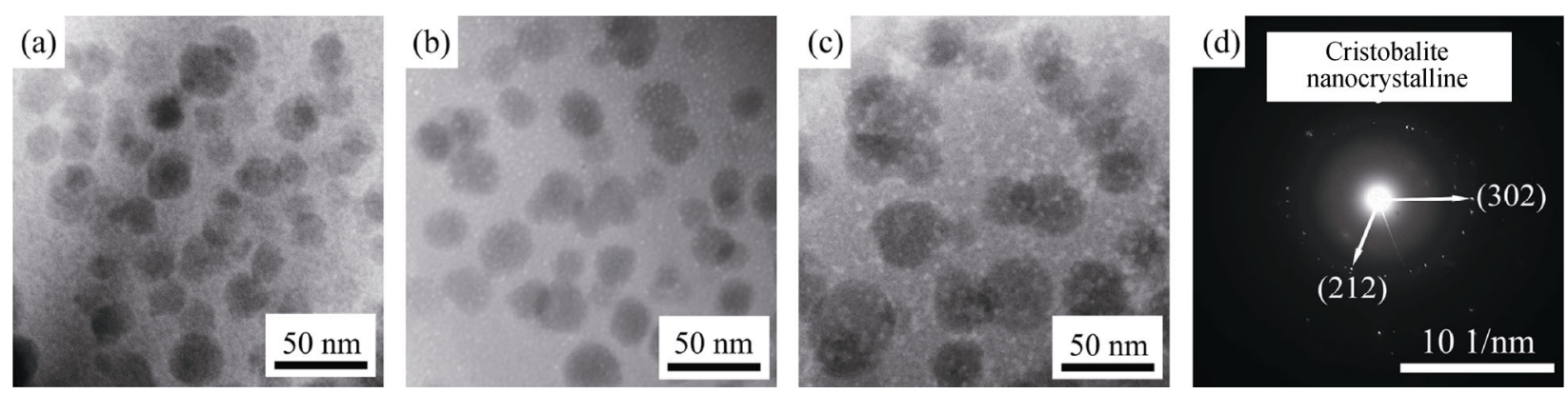

Fig. 4 Nanocrystalline precipitation microstructures in La-Al-Si-O glass phase of composite ceramics sintered under different temperatures: (a) 1500 , (b) 1700 , and (c) $1900{ }^{\circ} \mathrm{C}$; (d) diffraction patterns of amorphous phase and cristobalite nanocrystalline.

grains, which contributed to the improvement of densification. However, with the further increase of sintering temperature, h-BN grains had obvious growth, which led to the larger pores in the mutual framework by the large h-BN grains, resulting in the decrease of bulk density. Furthermore, some liquid phase was 


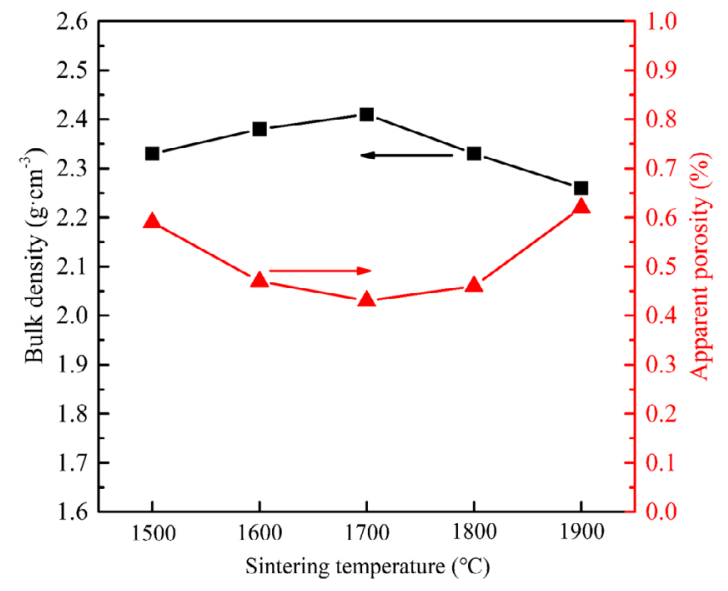

Fig. 5 Bulk densities and apparent porosities of $\mathrm{BN} / \mathrm{La}-\mathrm{Al}-\mathrm{Si}-\mathrm{O}$ composite ceramics.

extruded during hot-pressed sintering at $1900{ }^{\circ} \mathrm{C}$ because of the good fluidity of $\mathrm{La}-\mathrm{Al}-\mathrm{Si}-\mathrm{O}$ glass phase at high temperatures. Therefore, the glass phase content in the composition of this sample is less than that of other samples, leading to lower density and higher porosity.

Figure 6 shows mechanical properties of $\mathrm{BN} / \mathrm{La}-$ $\mathrm{Al}-\mathrm{Si}-\mathrm{O}$ composite ceramics sintered under different temperatures, including flexural strength, elastic modulus, and fracture toughness. With the increase of sintering temperature, the mechanical properties presented a small increase followed by a rapid decrease, which

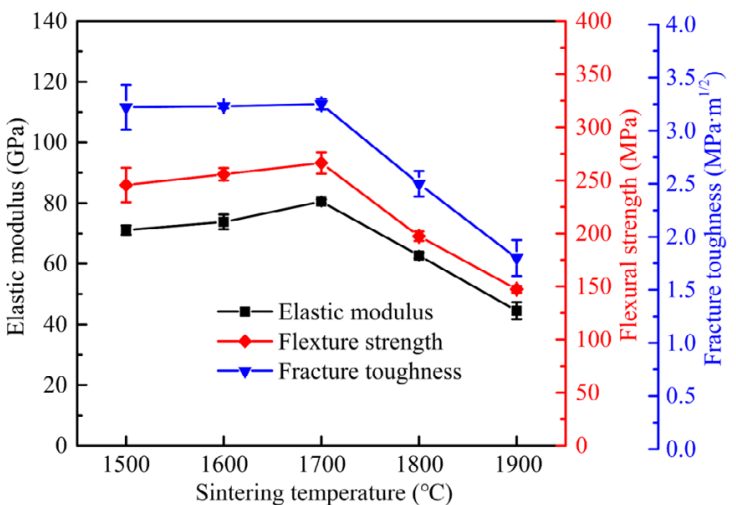

Fig. 6 Mechanical properties of $\mathrm{BN} / \mathrm{La}-\mathrm{Al}-\mathrm{Si}-\mathrm{O}$ composite ceramics.

was consistent with the tendency of bulk density. The best mechanical properties of $\mathrm{BN} / \mathrm{La}-\mathrm{Al}-\mathrm{Si}-\mathrm{O}$ composite ceramics were obtained under the sintering temperature of $1700{ }^{\circ} \mathrm{C}$. The elastic modulus, flexural strength, and fracture toughness were $80.5 \pm 0.7 \mathrm{GPa}, 266.4 \pm 10.1 \mathrm{MPa}$, and $3.25 \pm 0.05 \mathrm{MPa} \cdot \mathrm{m}^{1 / 2}$, respectively.

Fracture morphologies of $\mathrm{BN} / \mathrm{La}-\mathrm{Al}-\mathrm{Si}-\mathrm{O}$ composite ceramics sintered under different temperatures are shown in Figs. 7(a)-7(e). Digital Micrograph software was used to measure the grain size of $\mathrm{h}-\mathrm{BN}$ at the representative areas, and the average grain size was calculated from about 30 measured h-BN grains. The grain size increased significantly with increasing sintering temperature, and the statistically average
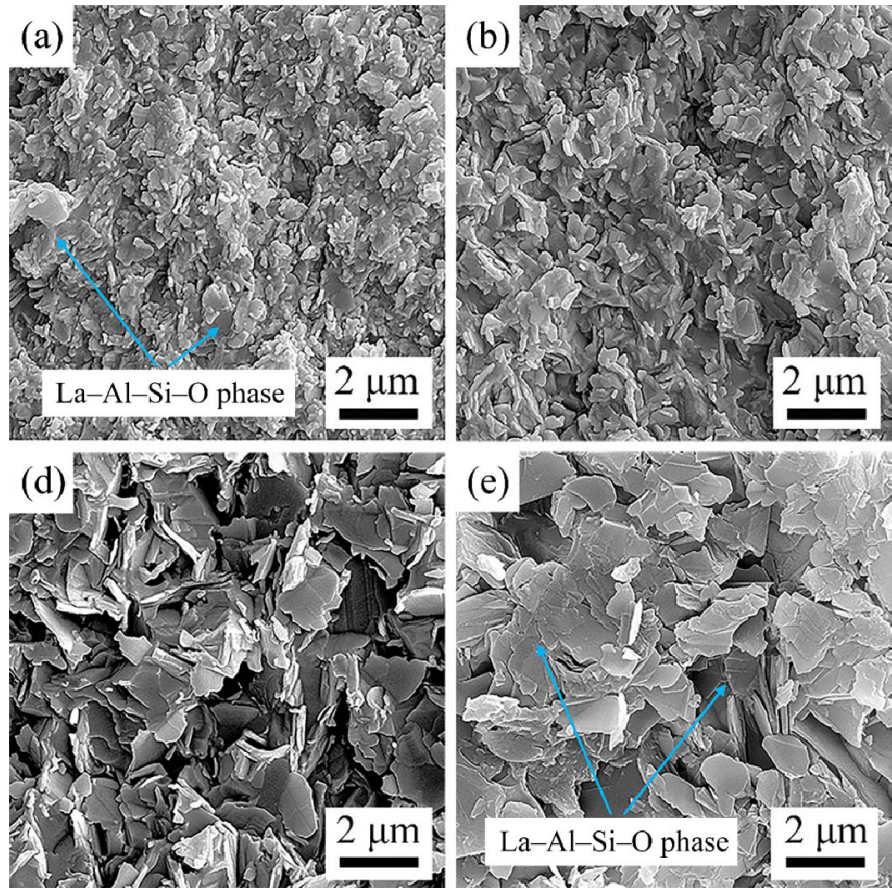

(e)

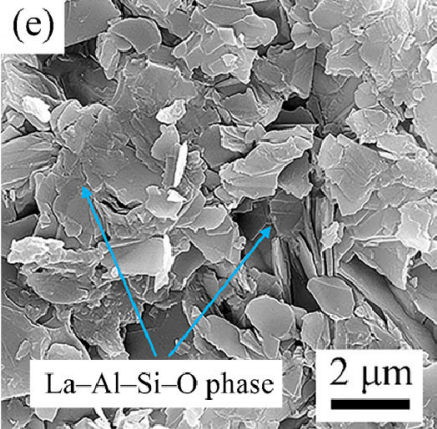

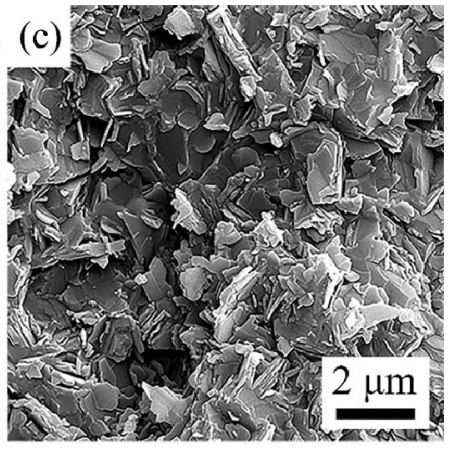

(f)

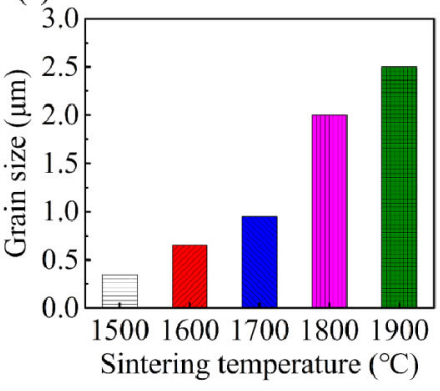

Fig. 7 Fracture morphologies of $\mathrm{BN} / \mathrm{La}-\mathrm{Al}-\mathrm{Si}-\mathrm{O}$ composite ceramics sintered under different temperatures: (a) 1500, (b) 1600, (c) 1700 , (d) 1800 , and (e) $1900{ }^{\circ} \mathrm{C}$; (f) statistics of average grain size. 
values are listed in Fig. 7(f). As the sintering temperature changed from 1500 to $1900{ }^{\circ} \mathrm{C}$, the average size of h-BN grains increased from 0.35 to $2.5 \mu \mathrm{m}$.

From the above results, we comprehensively analyzed the influence of sintering temperature on the mechanical properties of $\mathrm{BN} / \mathrm{La}-\mathrm{Al}-\mathrm{Si}-\mathrm{O}$ composite ceramics, which mainly included the following two points: (1) High sintering temperature facilitated heat transfer and atom diffusion in liquid phase, which were beneficial to liquid phase pore filling to increase the relative density and improve the mechanical properties; (2) the grain sizes of h-BN increased rapidly with the increase of sintering temperature, and when h-BN grains grew to larger size, the porosity of composite ceramics became higher, resulting in an adverse effect on the densifying process and mechanical properties.

The microstructural evolution process of $\mathrm{BN} / \mathrm{La}-\mathrm{Al}-$ $\mathrm{Si}-\mathrm{O}$ composite ceramics during hot-pressed sintering can be illustrated in Fig. 8. Firstly, the four raw powders were uniformly mixed and heated gradually in the graphite mold (Fig. 8(a)). When the sintering temperature increased, the $\mathrm{La}-\mathrm{Al}-\mathrm{Si}-\mathrm{O}$ liquid phase was formed and h-BN grains were uniformly distributed in the liquid phase environment (Fig. 8(b)). With the further increase of sintering temperature, the heat and mass transfer ability of the liquid phase was enhanced, and the h-BN grains began to grow significantly
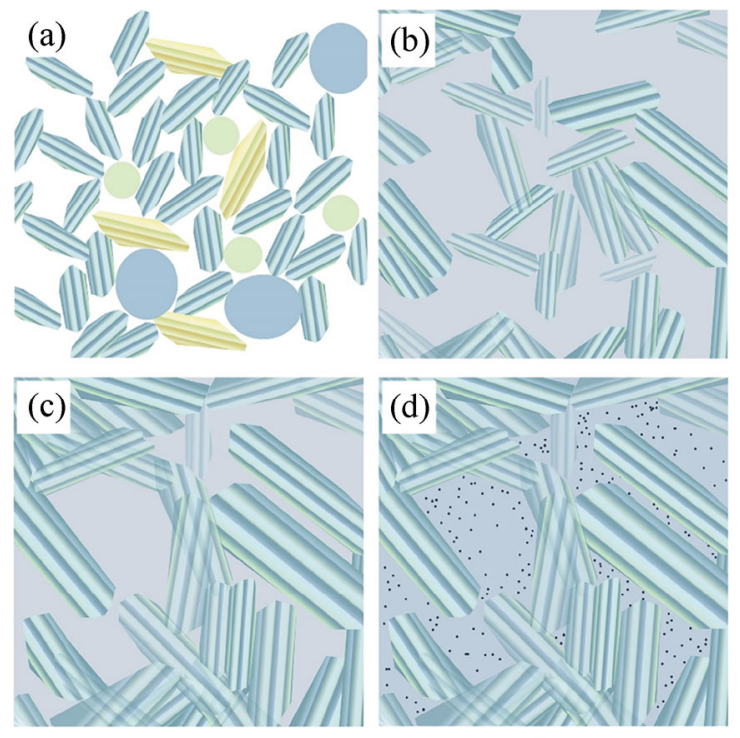

h-BN $\mathrm{La}_{2} \mathrm{O}_{3} \bigcirc \mathrm{SiO}_{2} \bigcirc \mathrm{Al}_{2} \mathrm{O}_{3} \cdot$ Cristobalite La-Al-Si-O phase

Fig. 8 Microstructural evolution mechanism diagrams of $\mathrm{BN} / \mathrm{La}-\mathrm{Al}-\mathrm{Si}-\mathrm{O}$ composite ceramics: (a) mixed raw powders, (b) La-Al-Si-O liquid phase formed, (c) h-BN grain growth, and (d) cristobalite nanocrystalline precipitation.
(Fig. 8(c)). At the case of sintering temperature increasing or holding time extending, the grain size of h-BN further grew. At the same time, the cristobalite phase nanocrystalline was also precipitated in the liquid phase (Fig. 8(d)). These microstructural evolution mechanisms of $\mathrm{BN} / \mathrm{La}-\mathrm{Al}-\mathrm{Si}-\mathrm{O}$ composite ceramics are consistent with Figs. 2-4.

\section{Conclusions}

The BN/La-Al-Si-O composite ceramics were hotpress sintered under different temperatures to reveal the microstructural evolution mechanisms. Ternary $\mathrm{La}-\mathrm{Al}-\mathrm{Si}-\mathrm{O}$ liquid phase was formed during the sintering process, which had a good wettability with h-BN grains and could effectively fill the pores to improve the densification of composite ceramics. Higher sintering temperature contributed to the growth and crystallization of h-BN grains through better heat transfer and atomic diffusion in liquid phase environment. Furthermore, cristobalite nanocrystals were precipitated from the liquid phase and also grow gradually with the increase of sintering temperature. The $\mathrm{BN} / \mathrm{La}-\mathrm{Al}-\mathrm{Si}-\mathrm{O}$ composite ceramics sintered under $1700{ }^{\circ} \mathrm{C}$ exhibited the best mechanical properties, which were attributed to the mutual influence of liquid phase environment, h-BN grain size, and precipitated phase.

\section{Acknowledgements}

This study was financially supported by the National Key Research and Development Program of China (No. 2017YFB0310400) and the National Natural Science Foundation of China (Nos. 52072089, 51672060, and 51832002).

\section{References}

[1] Eichler J, Lesniak C. Boron nitride $(\mathrm{BN})$ and $\mathrm{BN}$ composites for high-temperature applications. J Eur Ceram Soc 2008, 28: 1105-1109.

[2] Lipp A, Schwetz KA, Hunold K. Hexagonal boron nitride: Fabrication, properties and applications. J Eur Ceram Soc 1989, 5: 3-9.

[3] Perevislov SN, Slabov VS, Panteleev IB, et al. Chemical resistance of liquid-phase-sintered materials based on $\mathrm{Si}_{3} \mathrm{~N}_{4}$-BN. Glass Ceram 2020, 76: 451-456.

[4] Greil P. Advanced engineering ceramics. Adv Eng Mater 2002, 4: 247-254. 
[5] Chen JJ, Chen J, Wang S, et al. Tribological properties of h-BN matrix solid-lubricating composites under elevated temperatures. Tribol Int 2020, 148: 106333.

[6] Yadav V, Kulshrestha V. Boron nitride: A promising material for proton exchange membranes for energy applications. Nanoscale 2019, 11: 12755-12773.

[7] Li YZ, Chen F, Li XY, et al. Addition of h-BN for enhanced machinability and high mechanical strength of AlN/Mo composites. Ceram Int 2020, 46: 20097-20104.

[8] Smith EA. Graphite and boron nitride ("while graphite"): Aspects of structure, powder size, powder shape, and purity. Powder Metall 1971, 14: 110-123.

[9] Fang HM, Bai SL, Wong CP. "White graphene"-hexagonal boron nitride based polymeric composites and their application in thermal management. Compos Commun 2016, 2: 19-24.

[10] Ooi N, Rairkar A, Lindsley L, et al. Electronic structure and bonding in hexagonal boron nitride. J Phys: Condens Matter 2006, 18: 97-115.

[11] Ci L, Song L, Jin C, et al. Atomic layers of hybridized boron nitride and graphene domains. Nat Mater 2010, 9: 430-435.

[12] Duan XM, Yang ZH, Chen L, et al. Review on the properties of hexagonal boron nitride matrix composite ceramics. J Eur Ceram Soc 2016, 36: 3725-3737.

[13] Zhang GJ, Zou J, Ni DW, et al. Boride ceramics: Densification, microstructure tailoring and properties improvement. J Inorg Mater 2012, 27: 225-233. (in Chinese)

[14] Taylor KM. Hot pressed boron nitride. Ind Eng Chem 1955, 47: 2506-2509.

[15] Zhang GJ, Yang JF, Ando M, et al. Nonoxide-boron nitride composites: in situ synthesis, microstructure and properties. $J$ Eur Ceram Soc 2002, 22: 2551-2554.

[16] Marion JE, Hsueh CH, Evans AG. Liquid-phase sintering of ceramics. J Am Ceram Soc 1987, 70: 708-713.

[17] Duan XM, Jia DC, Wang Z, et al. Influence of hot-press sintering parameters on microstructures and mechanical properties of h-BN ceramics. $J$ Alloys Compd 2016, 684: 474-480.

[18] Zhang X, Chen JX, Li XC, et al. Microstructure and mechanical properties of h-BN/ $\mathrm{Y}_{2} \mathrm{SiO}_{5}$ composites. Ceram Int 2015, 41: 1279-1283.

[19] Gao XJ, Yan DM, Cao JW, et al. The study on the property and the microstructure of pressureless sintered h-BN ceramics. Adv Mater Res 2015, 1104: 9-14.

[20] Zhang ZT, Teng LD, Li WC. Mechanical properties and microstructures of hot-pressed MgAlON-BN composites. J Eur Ceram Soc 2007, 27: 319-326.

[21] Chen JJ, Chen JX. Formation and thermal stability of dual glass phases in the h-BN/SiO $2 / \mathrm{Yb}-\mathrm{Si}-\mathrm{Al}-\mathrm{O}$ composites. $J$ Eur Ceram Soc 2020, 40: 456-462.

[22] Zhang Z, Duan XM, Qiu BF, et al. Microstructure evolution and grain growth mechanisms of h-BN ceramics during hot-pressing. $J$ Eur Ceram Soc 2020, 40:
$2268-2278$.

[23] Zhai HZ, Cai HN, Yang XZ, et al. Preparation and properties of $\mathrm{BN}-\mathrm{SiO}_{2}$ composite ceramics. Key Eng Mater 2007, 336-338: 1426-1428.

[24] Tian Z, Wang Y, Zhang Z, et al. The effects of holding time on grain size, orientation degree and properties of h-BN matrix textured ceramics. Mater Chem Phys 2020, 248: 122916.

[25] Duan XM, Jia DC, Wu ZL, et al. Effect of sintering pressure on the texture of hot-press sintered hexagonal boron nitride composite ceramics. Scripta Mater 2013, 68: 104-107.

[26] Zhang Z, Duan XM, Qiu BF, et al. Preparation and anisotropic properties of textured structural ceramics: A review. J Adv Ceram 2019, 8: 289-332.

[27] Qiu BF, Duan XM, Zhang Z, et al. Microstructural evolution and mechanical properties of h-BN composite ceramics with $\mathrm{Y}_{2} \mathrm{O}_{3}-\mathrm{AlN}$ addition by liquid-phase sintering. Rare Met 2020, 39: 555-561.

[28] Wei DQ, Meng QC, Jia DC. Microstructure of hot-pressed h-BN/Si $\mathrm{N}_{4}$ ceramic composites with $\mathrm{Y}_{2} \mathrm{O}_{3}-\mathrm{Al}_{2} \mathrm{O}_{3}$ sintering additive. Ceram Int 2007, 33: 221-226.

[29] Niu B, Cai DL, Yang ZH, et al. Anisotropies in structure and properties of hot-press sintered h-BN-MAS composite ceramics: effects of raw h-BN particle size. $J$ Eur Ceram Soc 2019, 39: 539-546.

[30] Cai DL, Yang ZH, Duan XM, et al. Inhibiting crystallization mechanism of h-BN on $\alpha$-cordierite in BN-MAS composites. J Eur Ceram Soc 2016, 36: 905-909.

[31] Cai DL, Yang ZH, Duan XM, et al. Influence of sintering pressure on the crystallization and mechanical properties of BN-MAS composite ceramics. J Mater Sci 2016, 51: 2292-2298.

[32] Cai DL, Yang ZH, Duan XM, et al. A novel BN-MAS system composite ceramics with greatly improved mechanical properties prepared by low temperature hot-pressing. Mater Sci Eng: A 2015, 633: 194-199.

[33] Qiu BF, Duan XM, Zhang Z, et al. Microstructure and room/elevated-temperature mechanical properties of hotpressed h-BN composite ceramics with $\mathrm{La}_{2} \mathrm{O}_{3}-\mathrm{Al}_{2} \mathrm{O}_{3}-\mathrm{SiO}_{2}$ addition. J Eur Ceram Soc 2020, 40: 2260-2267.

[34] Iftekhar S, Grins J, Edén M. Composition-property relationships of the $\mathrm{La}_{2} \mathrm{O}_{3}-\mathrm{Al}_{2} \mathrm{O}_{3}-\mathrm{SiO}_{2}$ glass system. $J$ Non-Cryst Solids 2010, 356: 1043-1048.

[35] Li L, Tang ZJ. Phase diagram prediction of the $\mathrm{Al}_{2} \mathrm{O}_{3}-\mathrm{SiO}_{2}-\mathrm{La}_{2} \mathrm{O}_{3}$ system. J Mater Sci Tech 1999, 15: 439-443. (in Chinese)

[36] Marchi J, Morais DS, Schneider J, et al. Characterization of rare earth aluminosilicate glasses. J Non-Cryst Solids 2005, 351: 863-868.

[37] Iftekhar S, Grins J, Gunawidjaja PN, et al. Glass formation and structure-property-composition relations of the $\mathrm{RE}_{2} \mathrm{O}_{3}-\mathrm{Al}_{2} \mathrm{O}_{3}-\mathrm{SiO}_{2}(\mathrm{RE}=\mathrm{La}, \mathrm{Y}, \mathrm{Lu}, \mathrm{Sc})$ systems. $J \mathrm{Am}$ Ceram Soc 2011, 94: 2429-2435.

[38] Lorenz H, Orgzall I. Influence of the initial crystallinity on 
the high pressure-high temperature phase transition in boron nitride. Acta Mater 2004, 52: 1909-1916.

[39] $\mathrm{Wu} \mathrm{CW}$, Jean JH. Crystallization kinetics and dielectric properties of a low-fire $\mathrm{CaO}-\mathrm{Al}_{2} \mathrm{O}_{3}-\mathrm{SiO}_{2}$ glass + alumina system. J Am Ceram Soc 2016, 99: 2664-2671.

[40] Sadiki N, Coutures JP, Fillet C, et al. Crystallization of lanthanum and yttrium aluminosilicate glasses. $\mathrm{J} \mathrm{Nucl}$ Mater 2006, 348: 70-78.

Open Access This article is licensed under a Creative Commons Attribution 4.0 International License, which permits use, sharing, adaptation, distribution and reproduction in any medium or format, as long as you give appropriate credit to the original author(s) and the source, provide a link to the Creative Commons licence, and indicate if changes were made.

The images or other third party material in this article are included in the article's Creative Commons licence, unless indicated otherwise in a credit line to the material. If material is not included in the article's Creative Commons licence and your intended use is not permitted by statutory regulation or exceeds the permitted use, you will need to obtain permission directly from the copyright holder.

To view a copy of this licence, visit http://creativecommons.org/ licenses/by/4.0/. 